RESEARCH

Turkish Journal of Geriatrics

DOI: $10.31086 /$ tjgeri.2021.244

2021; 24(4): 463-477

\title{
FACTORS ASSOCIATED WITH PROLONGED MECHANICAL VENTILATION IN THE GERIATRIC POPULATION AND ITS EFFECT ON PATIENT OUTCOMES
}

- Mehmet Süleyman SABAZ ${ }^{1}$ - Sinan AŞAR $^{2}$

CORRESPONDANCE

${ }^{1}$ Mehmet Süleyman SABAZ

Marmara University Pendik Training and Research Hospital, Anesthesiology and Reanimation, Istanbul, Turkey

\section{Phone: +905064415710} e-mail: udmss_47@hotmail.com

Received: Nov 14, 2021

Accepted: Nov 30, 2021

${ }^{1}$ Marmara University Pendik Training and Research Hospital, Anesthesiology and Reanimation, Istanbul, Turkey

2 Health Science University Bakırköy Dr. Sadi Konuk Training and Research Hospital, Department of Anesthesiology and Reanimation, Istanbul, Turkey

\section{Abstract}

Introduction: This research aimed to identify the factors associated with prolonged mechanical ventilation in the growing geriatric patient population in the intensive care unit and to investigate its effect on patient outcomes.

Materials-Methods: In this retrospective study, the data of 1,501 patients aged 65 and over who were given mechanical ventilation support in the intensive care unit of a tertiary education and research hospital between January 2013 and January 2021 were obtained and evaluated electronically.

Results: Among the 1,501 patients, 1,289 (85.9\%) were non-prolonged mechanical ventilation and $212(14.1 \%)$ were prolonged mechanical ventilation. The frequency of chronic obstructive pulmonary disease and trauma was found to be higher in the prolonged mechanical ventilation patients $(p<0.05)$. The frequency of pressure wounds, acute kidney injury, and dialysis was higher in the prolonged mechanical ventilation group $(p<0.001)$. The mechanical ventilation pressure and respiratory rate per minute were higher in the prolonged mechanical ventilation patients. Intensive care unit mortality was $45.3 \%$ (96) in the prolonged mechanical ventilation patients and $49.9 \%$ (643) in the non-prolonged mechanical ventilation patients $(p>0.05)$. The mortality rates of the groups were similar in all admission diagnoses and age categories. A low glasgow coma scale, high partial pressure of carbon dioxide level, use of total parenteral nutrition, pressure sores, development of acute kidney injury, and dialysis were found to be associated with prolonged mechanical ventilation.

Conclusion: Prolonged mechanical ventilation causes morbidity in geriatric patients but is not associated with mortality.

Keywords: Respiration, Artificial; Ventilator Weaning; Geriatrics; Aged; Intensive Care Units. 


\section{INTRODUCTION}

Due to improvements in living conditions and progress in health services, the life expectancy of the geriatric population has increased significantly, and the mortality rate has decreased significantly in the last few decades (1). According to United Nations data, the number of the global elderly population, which was $8.3 \%$ in 2015 , will increase to $11.7 \%$ in 2030 and to $16 \%$ in 2050 (2). In parallel with the increase in the geriatric population in society, the number of geriatric patients admitted to the intensive care unit (ICU) is increasing (1). Approximately half of ICU admissions are patients over the age of 65 (3). In addition, the ICU readmission rate and mortality risk are higher in this patient group (3).

Advances in the management of geriatric patients admitted to the ICU have improved their survival, but this has led to the formation of a patient population with a long-term partial or full dependence on mechanical ventilators. The incidence of prolonged mechanical ventilation (PMV), defined by the National Association for Medical Direction of Respiratory Care (NAMDRC) as the need for mechanical ventilation (MV) for more than $6 \mathrm{~h}$ a day and for more than 21 consecutive days, varies between $6 \%$ and $28 \%$ in the literature (4-8). The number of patients in need of PMV is increasing day by day. Approximately 625,000 PMV patients were estimated in the United States in 2020 (9). Most of the data on PMV epidemiology has been obtained from ICU post-care or specialized weaning units (10). Data from acute ICU facilities are insufficient. In developing countries, due to the lack of specialized respiratory and MV separation units, these patients are constantly treated in acute ICUs. PMV consumes a significant amount of ICU resources in terms of intensive care beds, hospital staff, and costs $(5,11)$. In addition, it causes an emotional and financial burden on both the patient and the patient's family $(5,11,12)$.

The rapid increase in the number of geriatric patients and the improvement of critical care have caused an increased incidence of geriatric PMV patients who cannot be separated from MV. Thus, this study aimed to identify PMV-related factors in an increasing geriatric patient population in acute care ICU and to investigate their effect on patient outcomes.

\section{MATERIALS AND METHODS}

\section{Data Center}

This retrospective study was carried out in the Bakırköy Doctor Sadi Konuk Training and Research Hospital ICU, which serves as a third-level health center in Istanbul, Turkey. This center, in which intensive care specialists and assistants provide intensive care services as a closed unit on a $24 / 7$ basis, is controlled by the clinical decision support system (CDSS). It applies extracorporeal treatments and has a nurse-patient ratio of 1:2.

When a patient is admitted to the ICU, the patient's detailed anamnesis, comorbid diseases, and initial examination findings are recorded in the patient file created by the physician in the CDSS. All clothes and accessories on the patient are removed, and the patient's weight and height are measured by a nurse and entered into the patient's file. The disease severity scores used in the intensive care unit are calculated and recorded at regular intervals using the algorithms created in the patient file and with the approval of the physician. The ventilation parameters, such as the patient's fraction of inspired oxygen (FiO2), respiratory rate per minute, positive end-expiratory pressure (PEEP), Peak pressure, tidal volume, compliance, and work of breathing ventilator (WOBv), are instantly transferred to the CDSS and recorded through the communication between the mechanical ventilator and the system. The patient monitor information, laboratory test results, extracorporeal applications, and information on all infusions measured during the patient's ICU follow-up are transmitted to the clinical decision support system from the applied devices through the electronic ecosystem created. 


\section{Data Collection}

The data of patients admitted to the ICU between January 1, 2013 and January 1, 2021 were obtained from the CDSS (EMRall-OlinICU ImdSoft Metavision) with structured query language queries. The demographic characteristics of patients, such as age, gender, height, weight, body mass index (BMI), comorbid diseases, diagnosis and duration of hospitalization, average Acute Physiology and Chronic Health Evaluation II (APACHE II) calculated in the ICU, Simplified Acute Physiology Score III, Sequential Organ Failure Assessment Score (SOFA) values, average potential hydrogen $(\mathrm{PH})$ obtained from blood gas samples taken in the ICU, partial pressure of oxygen $\left(\mathrm{pO}_{2}\right)$, partial pressure of carbon dioxide $\left(\mathrm{pCO}_{2}\right)$, bicarbonate anion $(\mathrm{HCO} 3-)$, and lactate values, were analyzed. In addition, the treatments applied in the ICU and interventions, mechanical ventilation parameters, and mortality data were analyzed.

\section{Sample}

During the study period, a sample of geriatric patients who were followed up in the ICU was created. A total of 11,708 patients were admitted to the ICU during the study period. Among them, 5,663 patients were aged 65 and over. A total of 1,501 patients who needed MV for more than $24 \mathrm{~h}$ after the exclusion criteria were applied comprised the study sample (Figure 1). The criteria set by the NAMDRC were taken into account for the diagnosis of PMV (more than 6 hours of MV need per day and more than 21 consecutive days).

\section{Admission Criteria}

All patients over the age of 65 who received MV support in the ICU were included.

\section{Exclusion Criteria}

Patients younger than 65 years of age

Patients who do not need invasive MV

Patients who need MV for less than $24 \mathrm{~h}$

Patients who were taken to the service in the first $24 \mathrm{~h}$ in the ICU
Patients who developed mortality in the first 24 $h$ in the ICU

\section{Patients with missing data}

\section{Primary Results}

The primary aim of the study was to determine the factors associated with PMV and its effect on patient outcomes in geriatric patients hospitalized in the ICU.

\section{Secondary Results}

The secondary aim of the study was to compare the admission diagnoses, comorbidities, disease severity scores calculated in the ICU, interventions and treatments applied, laboratory parameters, length of stay, and ICU mortality in patients with and without PMV requirement.

\section{Ethical Issues}

Prior to the start of the research, ethical approval and permission from the institution were obtained from the ethics committee (Protocol code: 2021/448- Decision no: 2021-18-20) of Clinical Research at Bakırköy Dr. Sadi Konuk Training and Research Hospital.

\section{Statistical Analysis}

The data collected in the study were evaluated using SPSS 22.00. Categorical variables were expressed as the frequency (n) and percentage (\%), normally distributed numerical variables as the mean \pm standard deviation, and non-normally distributed numerical data as the median and interquartile ranges. Numerical data were analyzed using the independent samples t-test or Mann-Whitney $\mathrm{U}$ test. Categorical variables were analyzed using the chi-square test and Fisher's exact test when the conditions of the chi-square test were not met. A logistic regression model covering all patients was created to determine the risk of PMV. Kaplan-Meier survival analysis was used to determine the association of the groups with 28-day mortality. 
Figure 1. Flow diagram of patients selection

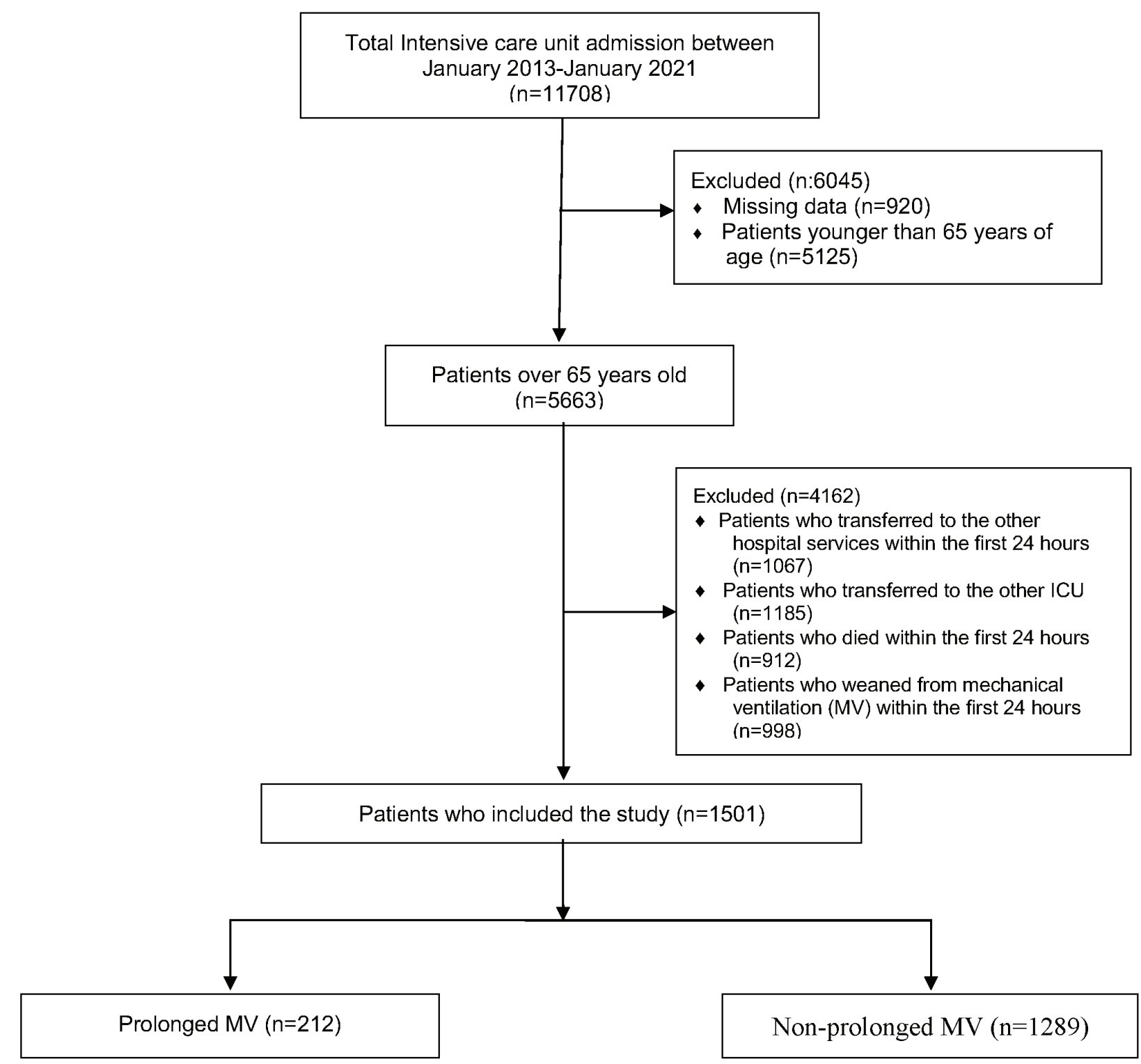

\section{RESULTS}

A total of 1,501 patients were analyzed. Among the study population, $47.9 \%$ (719) was female, and the mean age was $76.79 \pm 7.77$ years. The mean BMl was $27.54 \pm 5.46 \mathrm{~kg} / \mathrm{m} 2$. The obesity rate was determined to be $24 \%$ (360). The most common co- morbid disease was hypertension (782; 52.1\%), and the most common admission diagnosis was sepsis (476; 31.7\%). The APACHE II score of the patients was 26 (21-31). The median ICU length of stay was 6.45 (2.79-14.50) days. The mortality rate was $49.2 \%$ (739). As a result of the logistic regression model created to determine the factors associated with 
PMV in geriatric patients, a decrease in the Glasgow Coma Scale (GCS) was associated with PMV (OR: 1.063; Cl 95\%: 1.016-1.111). The development of acute kidney injury (AKI) increased the probability of PMV by 2.3 times (OR: 2.342; Cl 95\%: 1.506-3.643), and dialysis application increased by approximately 1.6 times (OR: 1.589; Cl 95\%: 1.079-2.339). The other parameters related to PMV were found to be associated with an increase in the pCO2 level and the use of TPN ( $p<0.05)$. The occurrence of pressure sores in geriatric patients increased the probability of PMV by approximately four times (OR: 4.033; Cl 95\%: 2.632-6.180). Mechanical power, which indicates the energy applied to the lung per unit time during MV, was not associated with PMV (Table 1).

\section{Comparison of the Clinical Features of the Groups}

The study population was divided into two groups according to the duration of MV: PMV and non-prolonged mechanical ventilation (NPMV). The general characteristics of the patients are shown in Table 2. Among the 1,501 patients, 1,289 (85.9\%) were NPMV, and 212 (14.1\%) were PMV. There was no difference between the groups in terms of age and gender. BMI was similar in both groups. The frequency of comorbidity was similar between the groups. No difference was observed between the groups in any of the comorbid diseases. When the admission diagnoses of the patients to the ICU were examined, sepsis was found to be the most common admission diagnosis in both groups. In the comparison between the groups, the proportion of patients with a diagnosis of sepsis was similar. The most common sepsis source in both groups was intraabdominal sepsis. The prevalence of chronic obstructive pulmonary disease (COPD) was more frequent in the PMV patients $(43 ; 20.3 \%)$ than in the NPMV patients $(213 ; 16.5 \%)(p<0.05)$. Trauma diagnosis was found to be higher in the PMV patients $(11 ; 5.2 \%)$ than in the NPMV patients $(24 ; 1.9 \%)(p<$ 0.05). There was no difference between the groups in other admission diagnoses. The other diagnoses common in both PMV and NPMV patients were pulmonary diseases and cerebrovascular diseases. The GCS, disease severity scores, and Richmond Agitation-Sedation Scale measured in the ICU were similar (Table 2).

\section{Laboratory Parameters}

The laboratory parameters of the patients are presented in Table 3. When blood gas values were

Table 1. The parameters associated with prolonged mechanical ventilation

\begin{tabular}{|l|c|c|c|}
\hline \multicolumn{1}{|c|}{ Parameters } & OR & Cl 95\% & P-value \\
\hline GCS & 1.063 & $1.016-1.111$ & 0.008 \\
\hline AKI & 2.342 & $1.506-3.643$ & $<0.001$ \\
\hline Dialysis & 1.589 & $1.079-2.339$ & 0.019 \\
\hline PCO $_{2}$ & 1.023 & $1.006-1.041$ & 0.010 \\
\hline Mechanical power & 1.067 & $0.986-1.155$ & 0.106 \\
\hline TPN & 1.864 & $1.274-2.729$ & 0.001 \\
\hline Pressure sores & 4.033 & $2.632-6.180$ & $<0.001$ \\
\hline
\end{tabular}

GCS: glascow coma score; $\mathrm{AKI}$ : acute kidney injury; $\mathrm{PCO}_{2}$ : partial pressure of carbon dioxide; TPN: total parenteral nutrition. 
Table 2. Characteristics of patients groups, admission diagnosis, scores, mechanical ventilator values, and blood parameters

\begin{tabular}{|c|c|c|c|}
\hline Parameters & $\begin{array}{c}\text { Non-prolonged MV } \\
n=1289(\% 85.9)\end{array}$ & $\begin{array}{l}\text { Prolonged MV } \\
n=212(\% 14.1)\end{array}$ & $P$-value \\
\hline Age (year) & $76.89 \pm 7.83$ & $76.16 \pm 7.36$ & 0.255 \\
\hline Age groups & & & 0.478 \\
\hline $65-74$ & $542(42.0)$ & $94(44.3)$ & \\
\hline $75-84$ & $495(38.4)$ & $84(39.6)$ & \\
\hline$\geq 85$ & $252(19.6)$ & $34(16.0)$ & \\
\hline Gender & & & 0.331 \\
\hline Female & $624(48.4)$ & $95(44.8)$ & \\
\hline Male & $665(51.6)$ & $117(55.2)$ & \\
\hline Body mass index $\left(\mathrm{kg} / \mathrm{m}^{2}\right)$ & 26.12(24.22-29.38) & $27.34(24.22-30.42)$ & 0.086 \\
\hline Obesity & $303(23.5)$ & $57(26.9)$ & 0.285 \\
\hline Comorbidity & $1201(93.2)$ & $200(94.3)$ & 0.528 \\
\hline Hypertension & $678(52.6)$ & $104(49.1)$ & 0.339 \\
\hline Diabetes & $363(28.2)$ & $61(28.8)$ & 0.854 \\
\hline Cerebrovascular disease & $156(12.1)$ & $19(9.0)$ & 0.187 \\
\hline CAD & $265(20.6)$ & $41(19.3)$ & 0.683 \\
\hline COPD & $213(16.5)$ & $43(20.3)$ & 0.178 \\
\hline CRF & 179(13.9) & $22(10.4)$ & 0.164 \\
\hline Malignancy & 175(13.6) & $20(9.4)$ & 0.096 \\
\hline Dementia & $93(7.2)$ & $11(5.2)$ & 0.282 \\
\hline Other & $136(10.6)$ & 23(10.8) & 0.896 \\
\hline \multicolumn{4}{|l|}{ Admission diagnosis } \\
\hline Cerebrovascular disease & $162(12.6)$ & $30(14.2)$ & 0.522 \\
\hline Cardiac & $101(7.8)$ & $12(5.7)$ & 0.266 \\
\hline
\end{tabular}




\begin{tabular}{|c|c|c|c|}
\hline Pulmonary & $238(18.5)$ & $54(25.5)$ & 0.017 \\
\hline Pneumonia & $142(11.0)$ & $27(12.7)$ & 0.463 \\
\hline COPD & $69(5.4)$ & $22(10.4)$ & 0.005 \\
\hline Pulmonary, other & $27(2.1)$ & $5(2.4)$ & 0.805 \\
\hline Renal-metabolic & $68(5.3)$ & $14(6.6)$ & 0.430 \\
\hline Trauma & $24(1.9)$ & $11(5.2)$ & 0.003 \\
\hline Sepsis & $413(32.0)$ & 63(29.7) & 0.501 \\
\hline Pneumosepsis & $85(6.6)$ & $11(5.2)$ & 0.438 \\
\hline İntra-abdominal sepsis & $218(16.9)$ & 28(13.2) & 0.177 \\
\hline Urosepsis & $29(2.2)$ & $5(2.4)$ & 0.921 \\
\hline Sepsis, other & $81(6.3)$ & $19(9.0)$ & 0.147 \\
\hline Malignancy & $82(6.4)$ & $11(5.2)$ & 0.512 \\
\hline Postoperative & $98(7.6)$ & $9(4.2)$ & 0.078 \\
\hline GIB-Hemorrhage & $44(3.4)$ & $4(1.9)$ & $0.297 *$ \\
\hline Other & $59(4.6)$ & $4(1.9)$ & $0.093^{*}$ \\
\hline \multicolumn{4}{|l|}{ Scores, median (IQR) } \\
\hline APACHE II & $26(20-31)$ & $26(22-31)$ & 0.241 \\
\hline APACHE IV & $94(69-119)$ & $92(76-114)$ & 0.560 \\
\hline SAPS III & $53(43-66)$ & $50(42-61)$ & 0.054 \\
\hline SOFA & $8(5-11)$ & $7(6-9)$ & 0.141 \\
\hline TISS & $21(16-26)$ & $22(17-27)$ & 0.139 \\
\hline GCS & $8(4-13)$ & $7(5-12)$ & 0.414 \\
\hline RASS & $-2(-5-0)$ & $-3(-4-0)$ & 0.263 \\
\hline
\end{tabular}

CAD: coronary artery disease; COPD: chronic obstructive pulmonary disease; CRF, chronic renal failure; GIB: gastrointestinal bleeding; APACHE: acute physiology and chronic health evaluation; SAPS: simplified acute physiology; SOFA: sequential organ failure assessment; TISS: therapeutic intervention scoring system; GCS: glascow coma score; RASS: Richmond Agitation and Sedation Scale; IQR: inter quartile range.

*: Fisher exact test 
examined, $\mathrm{PH}, \mathrm{pCO}_{2}$, and $\mathrm{HCO}_{3}$ levels were higher, and the $\mathrm{pO}_{2}$ and lactate levels were lower in the PMV patients $(p<0.001)$. Other laboratory parameters were similar, except that the thrombocyte levels were higher in the PMV group and that the hemoglobin and hematocrit levels were higher in the NPMV group.

\section{Mechanical Ventilation}

The duration of MV was 27.76 (23.00-38.12) days in the PMV group and 4.31 (2.02-8.07) days in the NPMV group. When the MV parameters were examined, the mean PEEP (5.7 [5.1-6.1]), peak pressure (15.2 [13.8-17.1]), respiratory rate (20 [18-22]), WOBv (1.12 [0.95-1.27]), and mechanical power (9.80 [8.83-11.05]) values were higher in the PMV group ( $p<0.05$ ). Mean pulmonary compliance, $\mathrm{FiO} 2$, tidal volume, and tidal volume values in $\mathrm{ml} / \mathrm{kg}$ calculated according to the ideal weight were similar between the groups (Table 3).

The interventions and treatments of the patients, and the complications developed are shown in Table 3. More arterial catheters $(178 ; 84.0 \%)$ and central venous catheters $(179 ; 84.4 \%)$ were inserted in the PMV patients $(p<0.001)$. The frequency of tracheostomy $(176 ; 83.0 \%)$ was higher in the PMV group ( $p<0.001)$. The use of antibiotics, vasoactive drug treatments, and TPN was higher in the PMV group ( $p<0.001$ ). Considering the complications that developed in the ICU, the AKI rate was higher in the PMV group $(168 ; 79.2 \%)$ than in the NPMV group $(825 ; 64.0 \%)(p<0.001)$. The frequency of dialysis was higher in the PMV group $(80 ; 37.7 \%)$ than in the NPMV group (320; $24.8 \%)(p<0.001)$. Pressure sores were more common in the PMV patients (76; 35.8\%) than in the NPMV patients $(114 ; 8.8 \%)(p$ $<0.001)$.

\section{ICU Duration and Mortality}

The PMV group (28.72 [23.67-38.52]) had longer ICU durations than the NPMV group (5.16 [2.4510.12]) ( $p<0.05)$. When the 90-day mortality was analyzed using the Kaplan-Meier survival analysis, survival time was found to be different between the groups (Figure 2; log-rank: $p<0.001$ ). Conversely, 90-day mortality and ICU mortality did not differ significantly between the groups. ICU mortality was 45.3\% (96) in the PMV patients and 49.9\% (643) in the NPMV patients $(p>0.05)$. The mortality rates of the groups were similar in all admission diagnoses and age categories (Table 3).

\section{DISCUSSION}

The results of this study investigating the factors associated with PMV in the geriatric patient population followed up in the ICU showed that low GCS, high $\mathrm{pCO}_{2}$ level, use of TPN, pressure sores, AKI development, and dialysis were associated with PMV. MV pressures were higher, and the respiratory rate per minute was greater in the PMV patients. In addition, WOBv and mechanical power values were higher in the PMV group. The frequency of PMV was higher in patients admitted with a diagnosis of COPD and trauma. The mortality rate of PMV patients was similar to that of NPMV patients. The results of the subgroup analyses showed that mortality rates were similar between the groups in all admission diagnoses.

Due to the changing demographic profile around the world, the majority of patients requiring intensive care in the future will be geriatric patients (3). Although MV is a life-saving intervention for the geriatric population, it can lead to various complications, such as ventilator-associated lung injury (VILI), ventilator-associated pneumonia, and prolonged hospitalization (13). These risks increase in patients who need PMV (13). There is no consensus on the definition of PMV. The PMV period in the published literature ranges from $5 \mathrm{~h}$ to 1 year, with the most common definition for PMV being greater than 21 days (14). The incidence of extended MV in acute ICUs varies, mainly depending on the long-term MV definition used. Based on the definition outlined in the NAMDRC, the incidence of prolonged MV was $14.1 \%$ (8). This rate varies from country to country. 
Figure 2. Kaplan-Meier analysis performed to determine the relationship between 90-day survival and prolonged mechanical ventilation (Log rank: $p<0.001$ )

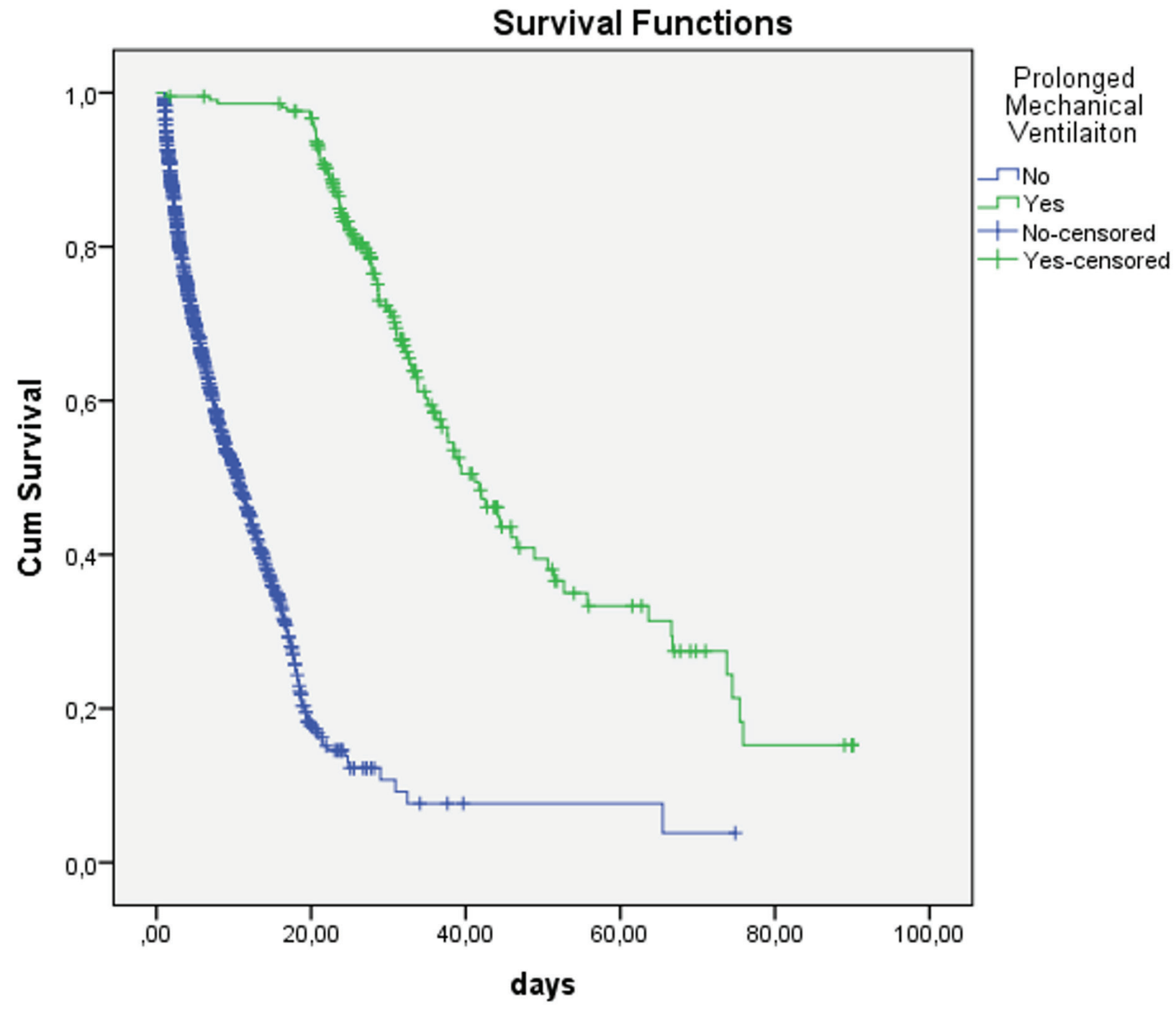

In previous studies, in which prolonged MV was defined as an MV $>21$ days, the rate of PMV was found to be $28 \%$ in India, $14 \%$ in Argentina, $6 \%$ in the United Kingdom, and $10 \%$ in Brazil (4-7). These variable results on PMV rates may be due to the different applications in health systems. In our study, the fact that all patients were followed up in the same acute ICU until discharge and that we did not have a specialized weaning unit could have caused the incidence of PMV to increase. Another factor associated with PMV is the patient profile. As our study was conducted in a tertiary referral center, the admission of patients with higher disease severity to the ICU could have increased the incidence of PMV.

The results of our study showed a mortality rate of $49.2 \%$ in geriatric patients. This rate is consistent 
Table 3. Interventions, treatments and mortality rates during the ICU stay.

\begin{tabular}{|c|c|c|c|}
\hline Parameters & $\begin{array}{c}\text { Non-prolonged MV } \\
\mathrm{n}=1289(\% 85.9) \\
\text { median (IQR) }\end{array}$ & $\begin{array}{c}\text { Prolonged MV } \\
\mathrm{n}=212(\% 14.1) \\
\text { median (IQR) } \\
\end{array}$ & $P$-value \\
\hline \multicolumn{4}{|l|}{ Mechanical ventilation } \\
\hline $\mathrm{FiO}_{2}(\%)$ & $42(40-48)$ & $43(40-46)$ & 0.554 \\
\hline $\operatorname{PEEP}\left(\mathrm{cmH}_{2} \mathrm{O}\right)$ & $5.4(5.1-5.9)$ & $5.7(5.1-6.1)$ & 0.004 \\
\hline P peak $\left(\mathrm{cmH}_{2} \mathrm{O}\right)$ & $14.4(12.7-16.4)$ & $15.2(13.8-17.1)$ & $<0.001$ \\
\hline Tidal Volume & $480(423-545)$ & 478(434-535) & 0.796 \\
\hline Tidal Volume (ml/kg) & $6.66(5.93-7.50)$ & 6.58(5.91-7.31) & 0.460 \\
\hline Respiratory rate (min) & $19(16-21)$ & $20(18-22)$ & $<0.001$ \\
\hline Compliance $\left(\mathrm{ml} / \mathrm{cmH}_{2} \mathrm{O}\right)$ & $37(30-46)$ & $35(29-45)$ & 0.181 \\
\hline WOBv (j/L) & $1.07(0.92-1.23)$ & $1.12(0.95-1.27)$ & 0.044 \\
\hline Mechanical power (J/min) & $9.12(7.62-10.78)$ & 9.80(8.83-11.05) & $<0.001$ \\
\hline \multicolumn{4}{|l|}{ Blood gas } \\
\hline $\mathrm{PH}$ & 7.37(7.28-7.43) & 7.39(7.34-7.44) & $<0.001$ \\
\hline $\mathrm{PO}_{2}(\mathrm{mmHg})$ & 89.8(67.5-113.0) & 81.4(62.0-99.7) & $<0.001$ \\
\hline $\mathrm{PCO}_{2}(\mathrm{mmHg})$ & $41.5(36.3-47.9)$ & $45.6(41.6-51.2)$ & $<0.001$ \\
\hline $\mathrm{HCO}_{3}(\mathrm{mEq} / \mathrm{L})$ & $23.9(20.0-28.1)$ & 28.5(24.9-32.4) & $<0.001$ \\
\hline Lactate (mmol/L) & $1.94(1.42-3.45)$ & $1.48(1.23-1.94)$ & $<0.001$ \\
\hline \multicolumn{4}{|l|}{ Laboratory } \\
\hline Glucose (mg/dl) & $148(125-185)$ & $151(131-182)$ & 0.207 \\
\hline Hemoglobin (g/dl) & $9.65(8.70-11.0)$ & 8.96(8.40-9.57) & $<0.001$ \\
\hline Hematocrit (\%) & 30.28(27.18-34.34) & 28.22(26.57-30.62) & $<0.001$ \\
\hline Platelet $\left(\times 10^{9} / \mathrm{L}\right)$ & 199(141-266) & $227(178-285)$ & $<0.001$ \\
\hline White blood cell $\left(\times 10^{9} / \mathrm{L}\right)$ & 13.2(9.85-17.56) & $12.51(10.19-15.18)$ & 0.056 \\
\hline Procalcitonin (ug/L) & $0.72(0.39-2.51)$ & $0.71(0.32-1.93)$ & 0.156 \\
\hline INR & $1.24(1.10-1.50)$ & $1.22(1.07-1.50)$ & 0.320 \\
\hline APTT (sec) & $32.7(27.3-43.0)$ & $32.1(27.2-41.9)$ & 0.565 \\
\hline AST (U/L) & $33(21-66)$ & $29(20-62)$ & 0.267 \\
\hline ALT (U/L) & $20(12-42)$ & $19(11-43)$ & 0.754 \\
\hline Creatinine (mg/dl) & $0.77(0.52-1.12)$ & $0.85(0.60-1.14)$ & 0.062 \\
\hline Albümine (mg/dl) & $2.79(2.29-3.30)$ & $2.94(2.49-3.40)$ & 0.007 \\
\hline
\end{tabular}




\begin{tabular}{|c|c|c|c|}
\hline Interventions & & & \\
\hline Arterial catheter & $989(76.7)$ & $178(84.0)$ & 0.019 \\
\hline Central catheter & $822(63.8)$ & $179(84.4)$ & $<0.001$ \\
\hline Tracheostomy & $206(16.0)$ & $176(83.0)$ & $<0.001$ \\
\hline Dialysis & $320(24.8)$ & $80(37.7)$ & $<0.001$ \\
\hline \multicolumn{4}{|l|}{ Treatments } \\
\hline Nutrition (kcal/day) & 1610(1420-1816) & $1701(1495-1899)$ & 0.064 \\
\hline TPN & $525(40.7)$ & $136(64.2)$ & $<0.001$ \\
\hline Antibiotics & $1197(92.9)$ & 212(100.0) & $<0.001^{*}$ \\
\hline Vasoactive agents & $960(74.5)$ & 187(88.2) & $<0.001$ \\
\hline \multicolumn{4}{|l|}{ Complications } \\
\hline AKI & $825(64.0)$ & $168(79.2)$ & $<0.001$ \\
\hline Stage I & $228(17.7)$ & $60(28.3)$ & $<0.001$ \\
\hline Stage II & $271(21.0)$ & $52(24.5)$ & 0.250 \\
\hline Stage III & $326(25.3)$ & $56(26.4)$ & 0.728 \\
\hline Pressure sores & $114(8.8)$ & $76(35.8)$ & $<0.001$ \\
\hline MV (day) & $4.31(2.02-8.07)$ & $27.76(23.00-38.12)$ & $<0.001$ \\
\hline LOS ICU (day) & $5.16(2.45-10.12)$ & 28.72(23.67-38.52) & $<0.001$ \\
\hline \multicolumn{4}{|l|}{ Mortality } \\
\hline Cerebrovascular disease & $60(37.0)$ & $8(26.7)$ & 0.275 \\
\hline Cardiac & $57(56.4)$ & $4(33.3)$ & $0.113^{*}$ \\
\hline Pulmonary & 105(44.1) & $25(46.3)$ & 0.771 \\
\hline Pneumonia & $69(48.6)$ & $15(55.6)$ & 0.507 \\
\hline COPD & $23(33.3)$ & $6(27.3)$ & 0.595 \\
\hline $\begin{array}{l}\text { Pulmonary, } \\
\text { Other }\end{array}$ & 13(48.1) & $4(80.0)$ & $0.208^{*}$ \\
\hline Renal-metabolic & $44(64.7)$ & $6(42.9)$ & 0.127 \\
\hline Trauma & $12(50.0)$ & 4(36.4) & $0.352^{*}$ \\
\hline Sepsis & $228(55.2)$ & $36(57.1)$ & 0.773 \\
\hline Pneumosepsis & $42(49.4)$ & $6(54.5)$ & 0.749 \\
\hline $\begin{array}{l}\text { Intra-abdominal } \\
\text { sepsis }\end{array}$ & 109(50.0) & $16(57.1)$ & 0.477 \\
\hline Urosepsis & $16(55.2)$ & $3(60.0)$ & $0.616^{*}$ \\
\hline
\end{tabular}




\begin{tabular}{|l|c|c|c|}
\hline \multicolumn{1}{|c|}{ Sepsis, other } & $61(75.3)$ & $11(57.9)$ & 0.128 \\
\hline Malignancy & $42(51.2)$ & $5(45.5)$ & 0.759 \\
\hline Postoperative & $35(35.7)$ & $4(44.4)$ & $0.427^{\star}$ \\
\hline GIB-Hemorrhage & $28(63.6)$ & $3(75.0)$ & $0.554^{\star}$ \\
\hline Other & $32(54.2)$ & $1(25.0)$ & $0.271^{\star}$ \\
\hline ICU mortality & $643(49.9)$ & $96(45.3)$ & 0.214 \\
\hline Age groups & & & \\
\hline $65-74$ & $258(47.6)$ & $36(38.3)$ & 0.095 \\
\hline $75-84$ & $249(50.3)$ & $42(50.0)$ & 0.959 \\
\hline$\geq 85$ & $136(54.0)$ & $18(52.9)$ & 0.910 \\
\hline
\end{tabular}

$\mathrm{FiO}_{2}$ : fraction of inspired oxygen; PEEP: positive end-expiratory pressure; WOBv: work of breathing ventilator; PCO2: partial pressure of carbon dioxide; PO2: partial pressure of oxygen; $\mathrm{HCO}_{3}$ : bicarbonate; CRP: C-reactive protein; INR: international normalized ratio; APTT: activated partial thromboplastin time; AST: aspartate aminotransferase; ALT: alanine aminotransferase; MV: mechanic ventilation; TPN: total parenteral nutrition; AKI: acute kidney injury; LOS: length of stay; ICU: intensive care unit. COPD: chronic obstructive pulmonary disease; GIB: gastrointestinal bleeding.

*: Fisher exact test

with previous study results. In a similar study, the mortality rate of ventilated intensive care patients over the age of 65 was found to be $53 \%$ (15). A meta-analysis showed that independent functional geriatric patients over 65 years of age admitted to the ICU had positive long-term outcomes and should not be excluded from intensive care (16). Our results showed that mortality did not increase among the geriatric PMV patients and that they had similar mortality rates to the NPMV patients. Therefore, advanced age should not be a criterion for refusing acute care for the elderly, including ventilation.

The improved quality of care in the ICU has led to many patients surviving after long-term treatments and to a rapid increase in the number of patients requiring long-term mechanical ventilation (PMV). The need for PMV in intensive care medicine is difficult to predict and is often based on clinical criteria, which are subjective and unreliable. Conventional techniques help clinicians estimate PMV by only $59 \%$ (17). Our research results revealed that GCS,
$A K I$, and dialysis are associated with PMV development. Low GCS is known to be associated with PMV. In a recent study, a low GCS score was shown to be an independent prognostic factor for both weaning failure and a higher in-hospital mortality rate in patients with acute stroke and brain trauma requiring PMV support (18). Another study found that having an $8 \leq$ GCS at the time of application was associated with PMV (19). Given that patients with low GCS cannot protect their airways and have a high risk of aspiration after extubation, it is not surprising that permanently impaired consciousness results in weaning failure and PMV. In examining the MV parameters of PMV patients, mechanical power, which collects different variables associated with VILI in a single parameter, was not associated with PMV, although the ventilation pressure and $W O B v$ values were higher. This suggests that the need for PMV may be related to the central respiratory impulse and the effectiveness of protective reflexes rather than ventilation dynamics. Another parameter associated with PMV in the geriatric population is 
the development of $\mathrm{AKI}$ and dialysis. In a previous study supporting our results, $\mathrm{AKI}$ and renal dysfunction were found to be important predictors of PMV (20). Moreover, the need for dialysis independently decreased the chances of successful weaning from MV (21).

Considering the other factors associated with PMV, the use of TPN and the development of pressure sores come to the fore. In critically ill patients, malnutrition and negative protein-energy balance are associated with longer ICU stay, mortality, rate of acquired infection, and duration of mechanical ventilation (22). Therefore, adequate calorie intake is important. Although TPN use is common in patients who do not have enough calories, TPN use is associated with an increased risk of infection. In addition, the effects of ageing, the presence of underlying chronic factors, and the critical illness itself can affect the skin of geriatric patients. Aside from vascular access difficulties in the PMV patients, the need for arterial and central venous catheterization increased compared with NPMV patients as a result of increased AKI development and TPN use. In addition to age-related changes in the skin, impaired circulation increases the risk of pressure sores and skin lacerations in these patients. Aside from the deterioration of the protective skin barrier, bypassing the intestines with the use of TPN, which has an important role in the immune response, and increased catheterization may increase complications, such as infection or bleeding in geriatric patients and prolonged MV and ICU stays.

Our results showed that the rate of PMV development is higher in patients with admission diagnoses of COPD and trauma. These findings are compatible with the literature. Patients with severe traumatic brain injury tend to have their airways protected by MV due to protective reflex dysfunction. Therefore, they are at greater risk of PMV than other diagnostic groups. Lung contusion, flail chest, and severe head trauma are possible important risk factors for MV support in multiple trauma patients. In a study conducted on patients with severe multiple injuries and blunt chest trauma, low GCS $(\leq 8)$ and flail chest were identified as independent risk factors for PMV (19). Consistent with our results, the presence of COPD has been found to be associated with PMV in many previous studies and has been shown to be an independent risk factor for mortality in critically ill patients $(20,21)$. The fact that PMV is associated with higher $\mathrm{pCO}_{2}$ and measured $\mathrm{pCO}_{2}$ levels in the PMV patients explains why PMV is more common in COPD patients. Consistent with our results, one study found that PMV patients showed a lower hypercapnic ventilation response than NPMV patients (23). In a meta-analysis of geriatric patients with COPD, elderly patients with respiratory failure are often underestimated and given inadequate care by healthcare professionals (24). According to a study that investigated factors associated with treatment outcomes in COPD and PMV patients, better long-term survival was associated with respiratory care (25). Therefore, COPD patients should not be deprived of ventilation, and the necessary respiratory support should not be withheld from these patients.

There are some limitations besides its strengths such as due to the acquisition of all data used in the study from electronic queries and CDSS preventing data loss and human errors, the inclusion of geriatric patients undergoing invasive mechanical ventilation only, and the large patient population. The fact that this study has a single-center population prevents the generalization of the results despite the geographical diversity of the patients. The retrospective study design could have caused the influence of confounding factors and the risk of bias. Moreover, for geriatric patients admitted to the ICU for MV, physicians could have been biased toward certain diagnoses (before or after the patient arrived in the ICU), and their approach to elderly patients with these diagnoses and experiencing respiratory failure could have varied. 


\section{CONCLUSION}

In the geriatric patient population followed up in the ICU, GCS, $\mathrm{pCO}_{2}$ level, TPN use, pressure sores, AKI development, and dialysis were associated with PMV. The frequency of PMV was higher in patients admitted with a diagnosis of COPD and trauma. In the PMV patients, the mortality rate was similar to that of the NPMV patients. The results of the subgroup analyses showed no difference in mortality between the groups in any admission diagnosis.

\section{REFERENCES}

1. Margaras V (2019) Demographic trends in EU regions. European Parliamentary Research Service, January 2019. [Internet]. Available from: https:// ec.europa.eu/futurium/en/system/files/ged/eprsbriefing-633160-demographic-trends-eu-regionsfinal.pdf. Accessed: 01.11.2021.

2. United-Nations Department of economic and social affairs. Population Division. World Population ageing 2019. Published by the United Nations; 2020. [Internet]. Available from: https://www.un.org/en/ development/desa/population/publications/pdf/ ageing/WorldPopulationAgeing2019-Report.pdf. Accessed: 01.11.2021.

3. Demirkıran H, Uzunoglu M, Erdivanlı B, et al. Prevalence and clinical features of chronic critical illness in the elderly population in Turkey. Turkish Journal of Geriatrics 2020;23 (4): 501-508. (DOI: 10.31086 / tjgeri.2020.188).

4. Muzaffar SN, Gurjar M, Baronia AK, et al. Predictors and pattern of weaning and long-term outcome of patients with prolonged mechanical ventilation at an acute intensive care unit in North India. Rev Bras Ter Intensiva 2017;29 (1): 23-33. (PMID: 28444069)

5. Lone NI, Walsh TS. Prolonged mechanical ventilation in critically ill patients: epidemiology, outcomes and modelling the potential cost consequences of establishing a regional weaning unit. Crit Care 2011;15 (2): R102. (PMID: 21439086)

6. Loss SH, de Oliveira RP, Maccari JG, et al. The reality of patients requiring prolonged mechanical ventilation: a multicenter study. Rev Bras Ter Intensiva 2015;27 (1): 26-35. (PMID: 25909310)

7. Damuth E, Mitchell JA, Bartock JL, Roberts BW,
The elimination of the potential causes of PMV development in geriatric patients to be followed up in the ICU and attention to the early prediction of PMV may improve ICU outcomes in this patient population.

Conflict of Interest: The authors declare they have no conflict of interest.

Funding: The authors declared that this study received no financial support.

Trzeciak S. Long-term survival of critically ill patients treated with prolonged mechanical ventilation: a systematic review and meta-analysis. Lancet Respir Med 2015;3 (7): 544-53. (PMID: 26003390)

8. Maclntyre NR, Epstein SK, Carson S, Scheinhorn D, Christopher K, Muldoon S; National Association for Medical Direction of Respiratory Care. Management of patients requiring prolonged mechanical ventilation: report of a NAMDRC consensus conference. Chest 2005;128 (6): 3937-54. (PMID: 16354866)

9. Zilberberg MD, de Wit M, Shorr AF. Accuracy of previous estimates for adult prolonged acute mechanical ventilation volume in 2020: update using 20002008 data. Crit Care Med 2012;40 (1): 18-20. (PMID: 21926594)

10. Scheinhorn DJ, Hassenpflug MS, Votto JJ, et al. Post-ICU mechanical ventilation at 23 long-term care hospitals: a multicenter outcomes study. Chest 2007;131 (1): 85-93. (PMID: 17218560)

11. Nelson JE, Cox CE, Hope AA, Carson SS. Chronic critical illness. Am J Respir Crit Care Med 2010;182 (4): 446-54. (PMID: 20448093)

12. Cameron JI, Chu LM, Matte A, et al. One-Year Outcomes in Caregivers of Critically III Patients. N Engl J Med 2016;374 (19): 1831-41. (PMID: 27168433)

13. Clark PA, Lettieri CJ. Clinical model for predicting prolonged mechanical ventilation. J Crit Care 2013;28 (5): 880.e1-7. (PMID: 23683556)

14. Rose L, McGinlay M, Amin R, et al. Variation in Definition of Prolonged Mechanical Ventilation. Respir Care 2017;62 (10): 1324-1332. (PMID: 28611229)

15. Lieberman D, Nachshon L, Miloslavsky O, et al. Elderly patients undergoing mechanical ventilation in and out of intensive care units: a comparative, pro- 
spective study of 579 ventilations. Crit Care 2010;14 (2): R48. (PMID: 20353552)

16. Marik PE. Should age limit admission to the intensive care unit? Am J Hosp Palliat Care 2007;24 (1): 63-6. (PMID: 17347508)

17. Parreco J, Hidalgo A, Parks JJ, Kozol R, Rattan R. Using artificial intelligence to predict prolonged mechanical ventilation and tracheostomy placement. J Surg Res 2018;228: 179-187. (PMID: 29907209)

18. Huang HY, Lee CS, Chiu TH, et al. Clinical outcomes and prognostic factors for prolonged mechanical ventilation in patients with acute stroke and brain trauma. J Formos Med Assoc 2021:S0929-6646 (21)00075-9. (PMID: 33750622).

19. Okabe Y. Risk factors for prolonged mechanical ventilation in patients with severe multiple injuries and blunt chest trauma: a single center retrospective case-control study. Acute Med Surg 2018;5 (2): 166172. (PMID: 29657729)

20. Ghauri SK, Javaeed A, Mustafa KJ, Khan AS. Predictors of prolonged mechanical ventilation in patients admitted to intensive care units: A systematic review.
Int J Health Sci (Qassim) 2019;13 (6): 31-38. (PMID: 31745396)

21. Estenssoro E, González F, Laffaire E, et al. Shock on admission day is the best predictor of prolonged mechanical ventilation in the ICU. Chest 2005;127 (2): 598-603. (PMID: 15706002)

22. Rasheed S, Woods RT. Malnutrition and quality of life in older people: a systematic review and meta-analysis. Ageing Res Rev 2013;12 (2): 561-6. (PMID: 23228882)

23. Lee CS, Chen NH, Chuang LP, et al. Hypercapnic Ventilatory Response in the Weaning of Patients with Prolonged Mechanical Ventilation. Can Respir J 2017;2017: 7381424. (PMID: 29213205)

24. Sevransky JE, Haponik EF. Respiratory failure in elderly patients. Clin Geriatr Med 2003;19 (1): 205-24. (PMID: 12735123)

25. Quinnell TG, Pilsworth S, Shneerson JM, Smith IE. Prolonged invasive ventilation following acute ventilatory failure in COPD: weaning results, survival, and the role of noninvasive ventilation. Chest 2006;129 (1):133-9. (PMID: 16424423) 